\title{
Stereotactic vacuum-assisted breast biopsy (SVAB) in the management of suspicious calcifications
}

López-Ruiz JA ${ }^{1 *}$, Sánchez-González $\mathbf{M}^{2}$, Aguirre Larracoechea $\mathrm{U}^{3}$, Zabalza-Estévez $\mathrm{I}^{4}$, Basarrate-Salazar $\mathbf{I}^{5}$, Fernández-Temprano $Z^{2}$ and Quintana-López JM $\mathbf{J M}^{3}$

${ }^{1}$ Preteimagen Radiologic Centre: Breast Imaging, Spain

${ }^{2}$ Radiology Department. Galdakao Hospital, Spain

${ }^{3}$ Epidemiology Department. Galdakao Hospital, Spain

${ }^{4}$ Pathology Department. Galdakao Hospital, Spain

${ }^{5}$ Radiology Department. San Eloy's Hospital, Spain

\begin{abstract}
Objectives: Stereotactic vacuum assisted breast biopsy (SVAB) is the most efficient and habitual method for the management of suspicious calcifications. However, it's a not perfect method: false negatives cases can be observed, and some malignant lesions may be underestimated. Our purpose is to evaluate the diagnostic value of stereotactic vacuum-assisted breast biopsy (SVAB) in the management of suspicious calcifications, without associated mass.

Materials and methods: Retrospective review of 1,106 procedures of SVAB performed on a prone digital table on calcifications without associated mass classified as BI-RADS 3, 4 or 5. The samples were analysed in the same laboratory of pathology. In situ lobular carcinomas have been considered malignant lesions. The "gold standard" has been the pathological analysis after surgery, and/or the follow-up for a minimum of 2 years. The following variables were evaluated: age, diagnostic category, size of lesions, number of samples extracted and diagnostic parameters: Sensitivity, Specificity, Positive Predictive Value (PPV), Negative Predictive Value (NPV) and Accuracy.

Results: The average age has been 52.75 years. According to the diagnostic category, $28.03 \%$ of cases corresponded to category $3,57.32 \%$ to category 4 and $14.65 \%$ to category 5. The PPV was $14.84 \%, 35.80 \%$ and $93.21 \%$, for category 3 , 4 and 5, respectively, with an average PPV of $38.34 \%$. A sensitivity of $96.81 \%$, specificity of $100 \%$, VPP of $100 \%$, VPN of $98.28 \%$ and an accuracy of $98.87 \%$ were obtained. $1.47 \%$ of false negatives and $4.76 \%$ of underestimation have been observed.

Conclusion: A high indication for category 3 calcifications cluster is observed, since most patients prefer to undergo the procedure, rather than radiological follow-up. The PPV observed in category 3 (14.84\%) is higher than that reported "officially" (2\%), probably due to the great inter-observer variability.
\end{abstract}

\section{Introduction}

Vacuum Assisted Biopsy (VAB) is a percutaneous breast biopsy procedure which can be used in the management of non-palpable breast lesions with a variable degree of suspicion, that's, those classified with the BI-RADS ("Breast Imaging Reporting and Data System") categories 3,4 or 5 [1].

Several studies emphasize a better surgical pathological correlation of $\mathrm{VAB}$ with respect to other percutaneous methods such as the usual core biopsy, in which variable percentages of underestimation (in relation to the infiltration status in breast cancer) and false negatives cases (in benign, borderline or high-risk lesions: atypical epithelial hyperplasia, papillomatosis, radial scar) have been described [2-5]. Therefore, a majority of authors [5-7] consider that VAB is especially indicated in the percutaneous biopsy of calcifications without associated mass.

Although several studies have been reported about the eco-guided $\mathrm{VAB}[8,9]$, or by means of digital tomosynthesis [10], the vast majority of procedures are still performed using a stereotactic guide.

The current use of VAB has demonstrated, once again, the interobserver variability $[11,12]$ to assess the diagnostic category as well as the existence of different protocols for the management of same type of image (for example, the clusters of calcifications classified as
BI-RADS 3), so the Positive Predictive Value (PPV) in the reported series is quite variable $[11,13-16]$. In the present work, we performed a retrospective review of our results, regarding the diagnostic value of stereotactic vacuum-assisted breast biopsy (SVAB) in the management of calcifications classified as BI-RADS 3, 4 and 5. We also reviewed the literature on this subject and we compared the results for our study with those of other authors.

\section{Materials and methods}

We retrospectively reviewed the activity of our breast digital stereotactic Unit, which included performing 2,078 consecutive procedures, of which 1,693 (81.47\%) corresponded to calcifications without other accompanying radiological signs, although only the results corresponding to 1,106 procedures with complete data (followup and /or surgery) have been evaluated.

${ }^{\star}$ Correspondence to: Jose A. López-Ruiz, Preteimagen Radiologic Centre: Breast Imaging, Bilbao, Spain, Tel: 34-944-437-499, Fax: 34-944-437-997, E-mail: jalopez@preteimagen.com

Key words: biopsy, breast, vacuum assisted, stereotactic, calcifications

Received: June 10, 2018; Accepted: June 23, 2018; Published: June 28, 2018 
The unit carries out its activity in a private practice and provides healthcare to patients referred from various medical centers (public concerted and private), and therefore with mammographic images evaluated by different radiologists with variable experience in breast imaging.

The assessment of the BI-RADS diagnostic category has been carried out prospectively by the radiologist of the petitionary center who indicated the SVAB, or one of the two radiologists of the unit, in the absence of an assignment of category by the former. The BIRADS nomenclature system (1) has been taken into account, although subcategories $(A, B, C)$ have not been distinguished within BI-RADS lesions 4 .

The SVAB was performed by one of the two radiologists of the unit in a digital prone table, and its histological analysis was carried out in the same laboratory of Pathology, in all cases.

The Mammotome system (11G gauge), or the Vacora system (10G gauge), indistinctly, have been used. The main purpose of the unit has been to obtain a representative and diagnostic sample of the lesion to be studied, according to the radiologist's criteria, which does not necessarily imply the total extraction of the calcifications clusters.

The samples containing calcifications were not separated from those that did not contain them, and all together they were collected in a "cassette", fixed in formalin and sent to the same pathology laboratory. Ductal and intralobular carcinomas in situ have been considered malignant lesions in the present study.

The parameters included in the present study were: age, diagnostic category (according to BI-RADS system), size of images, number of samples extracted and diagnostic value of SVAB: sensitivity, specificity, Positive Predictive Value (PPV), Negative Predictive Value (NPV) and accuracy. We have also evaluated the underestimation (in situ vs. infiltrating carcinoma) and False Negatives (benign $v s$. malignant lesion).

The size of the images has been distributed as follows: less than $10 \mathrm{~mm}, 10-20 \mathrm{~mm}$ and greater than $20 \mathrm{~mm}$. The underestimation was considered in cases in which SVAB diagnosed malignant lesion in situ and post-surgical pathological analysis revealed the presence of infiltrating or "micro-infiltrating" areas.

False Negative cases were those in which SVAB diagnosed benignity (including "borderline" or "high risk" lesions), and subsequently malignant (invasive or non-invasive) lesion was observed either at follow-up or surgery.

The "gold standard" has been the pathological analysis after surgery or the radiological follow-up (for a minimum period of 2 years).

Statistical calculations were performed with the statistical package SAS System v9.1, assuming statistical significance when $p<0.05$.

\section{Results}

\section{Age}

For descriptive and multivariate correlation, the age was distributed as follows: patients younger than 50 years, 50 to 64 years, and over 64 years, which is $42.32 \%, 45.63 \%$ and $12.05 \%$, respectively. The average age was 52.75 years.

\section{Diagnostic category of lesions (Table 1)}

The majority of cases (57.32\%) corresponded to category 4, followed by category 3 (28.03\%) and category 5 (14.65\%).
Table 1. Positive predictive value (PPV) and diagnostic category (1.106 Cases)

\begin{tabular}{|c|c|c|c|}
\hline Category & \multicolumn{2}{|c|}{ Surgery / Follow-Up } & Total (\%) \\
\hline $\begin{array}{c}\text { BI-RADS 3 } \\
\text { (PPV) }\end{array}$ & $\begin{array}{c}46 \\
(14.84 \%)\end{array}$ & 264 & $310(28.03 \%)$ \\
\hline $\begin{array}{c}\text { BI-RADS } 4 \\
\text { (PPV) }\end{array}$ & $\begin{array}{c}227 \\
(35.80 \%)\end{array}$ & 407 & $634(57.32 \%)$ \\
\hline $\begin{array}{c}\text { BI-RADS 5 } \\
\text { (PPV) }\end{array}$ & $\begin{array}{c}151 \\
(93.21 \%)\end{array}$ & 11 & $162(14.65 \%)$ \\
\hline $\begin{array}{c}\text { TOTAL } \\
\text { (PPV AVERAGE) }\end{array}$ & $\begin{array}{c}424 \\
(38.34 \%)\end{array}$ & 682 & 1.106 \\
\hline
\end{tabular}

BI-RADS: Breast Imaging Reporting and Data System

\section{Size of the images}

The majority (54.98\%) were lesions smaller than $10 \mathrm{~mm}$.

\section{Number of samples extracted}

In $35.99 \%$ of cases, between 9 and 12 samples were obtained, followed by $27.89 \%$ of cases, in which 5 to 8 were obtained.

\section{Diagnosis obtained in the SVAB sample (Table 1)}

The Positive Predictive Value (PPV) for breast cancer for Category 3,4 and 5 lesions were $14.84 \%, 35.80 \%$ and $93.21 \%$, respectively, with an average PPV of $38.34 \%$.

\section{Diagnostic parameters of the SVAB}

The sensitivity of method was $96.81 \%$, specificity $100 \%$, Positive Predictive Value (VPP) 100\%, Negative Predictive Value (NPV) 98.28\% and accuracy $98.87 \%$. There were no significant differences between the two radiologists of the unit.

\section{Diagnostic value of the SVAB to establish the infiltrant character vs non infiltrant of the malignant lesions}

It has been estimated on 189 cases, in which complete information is available. In 9 cases, the infiltrating nature of the malignant lesion was underestimated, representing $4,76 \%$ of all cases in which SVAB diagnosed a non-infiltrating tumour. Diagnostic category corresponded to BI-RADS 3 (2 cases), BI-RADS 4 ( 5 cases) and BI-RADS 5 ( 2 cases).

\section{Analysis of false negative cases}

Among the 682 cases in which the SVAB diagnosed benignity (Table 1), there have been 10 false negative cases, which represent a rate of $1.47 \%$. The 10 false negative cases were lesions smaller than 10 $\mathrm{mm}$ (8 cases), and greater than $20 \mathrm{~mm}$ ( 2 cases). According to their diagnostic category, corresponded to BI-RADS 3 (3 cases), BI-RADS 4 ( 6 cases), and BI-RADS 5 ( 1 case). It should be mentioned that, in 3 cases, the diagnoses obtained in SVAB were considered "high-risk" lesions: atypical epithelial hyperplasia (2 cases) and papillomatosis (1 case). In the surgical analysis, 8 cases corresponded to non-infiltrating malignant lesions.

\section{Univariant and multivariant analysis}

In the univariant analysis of the factors taken into account to estimate the profile of the patient at risk of obtaining a diagnosis of malignancy, Age is not associated with risk. Lesions smaller than 10 $\mathrm{mm}$ had a lower risk of malignancy, compared with those greater than $20 \mathrm{~mm}$. $(p<0.001)$. The risk of malignant lesion increases as the diagnostic category (BI-RADS) increases.

In the multivariate analysis it is observed that age has not proved to be a predictor of malignancy. Lesions with a size between 10 and 20 
$\mathrm{mm}$ had a higher risk of malignancy than those larger than $20 \mathrm{~mm}$. As we have seen in the univariate analysis, the correlation between risk of malignancy and the assigned diagnostic category (BI-RADS) was significant.

\section{Discussion}

Breast calcifications (also known as "microcalcifications" in the clinical-radiological "slang"), are usually of the dystrophic type [17], regardless of the underlying (benign or malignant) cause. Although they can be located in any breast tissue, those that accompany the malignant processes are usually located in the epithelial tissue, both in ductal and lobular structures, although the intimate mechanism of its formation in the malignant processes is not well known, proposing diverse hypotheses [17-19]. Nevertheless, calcifications have not been localized within the malignant tissue in some cases of carcinomas accompanied by calcifications in mammography [20].

Two types have been described, according to their chemical composition [21,22]. In Type I, calcifications are composed of calcium oxalate, while Type II calcifications are composed of calcium phosphate / hydroxyapatite. Malignant processes are associated more frequently with those of Type I [21], although this classification presents little practical importance from a radiological point of view.

They are frequently seen on mammograms, and usually translate the presence of benign processes. However, they can also be observed, as the only finding, in $34.5 \%$ of the malignant lesions detected in the mammographic screening [23].

Its radiological aspect may offer variable features of suspicion and, therefore, require pathological analysis. Until a few years ago, this meant a diagnostic surgical procedure, although the advent of the percutaneous biopsy was a great advance, equally effective and much more efficient [7]. Limitations of fine needle aspiration (FNA) and usual core-biopsy were soon demonstrated in the management of calcifications without associated mass, limitations that were largely overcome by the startup of vacuum assisted biopsy (VAB), procedure of choice today [5-7].

Although some ecoguided VAB procedures have recently been reported (with good results $[8,9]$ ), stereotactic guidance and, more recently, tomosynthesis [10], have been used in most situations.
Classically, SVAB is mainly contemplated in the management of category 4 and 5 calcifications [5,24-26], although in the last editions of the BI-RADS system [1] it is referred to some category 3 "special situations", where percutaneous biopsy would also be indicated.

On the other hand, there are some authors who document interobserver variability in the classification of lesions [11,12], and how computer-assisted reading can modify the initial assessment of the diagnostic category, (especially in category 3 lesions of the BI-RADS system) into higher categories [27].

The $57.32 \%$ of our cases (Table 1) corresponded to category 4 lesions, according to data from other published series, in which the main indication for SVAB was lesions of this type and diagnostic category [20-22]. It is noteworthy, however, that 310 cases $(28.03 \%)$ were classified as category 3 . We believe that this reflects a remarkable inter-observer variability (probably linked to experience and training degree among the various radiologists who indicate the biopsy) and the patients preference. In our opinion, if we explain to patients the "true" meaning of category 3 lesions (probability of malignancy not greater than $2 \%$ ), as well as the different alternatives for their diagnostic management (follow-up vs. percutaneous biopsy), most of them will prefer the percutaneous biopsy, especially if the biopsy procedure is easily accessible, as is the case of the patients in our study.

In our review, we found an average Positive Predictive Value (PPV) for malignancy of $38.34 \%$ (Table 1), higher than reported in other series [11-16,28-34] (Table 2). Note the PPV rate of the category $3(14.84 \%)$, much higher than the classic percentage (not higher than $2 \%)$, reported in the BI-RADS nomenclature system [1]. In the literature consulted frequently found the finding of PPV rate greater than $2 \%$ in this category, to rates even higher than ours (Table 2), such as those reported by Kikuchi M et al. [13], in which $23.72 \%$ of PPV rate is cited for category 3 calcifications.

The number of samples extracted by SVAB, as well as the percentage of removal of the lesion, have been discussed in some papers consulted $[6,24,35,36]$, with references to the desirability of obtaining a minimum number of samples to achieve the best results. Lomoschitz et al. [34] obtained very acceptable results with an average of 12 samples. In our review, the number of samples more common resembles that of the work of Lomoschitz et al. and has been between 9 and 12 (35.99\% of cases), and between 5 and 8 (27.89\%). About the required number of

Table 2. Diagnostic category and PPV: Comparison with other series

\begin{tabular}{|c|c|c|c|c|c|}
\hline SERIES & $\mathbf{n}$ & BI-RADS 3 & BI-RADS 4 & BI-RADS 5 & AVERAGE \\
\hline Mendez A et al. [12] & 91 & $6.50 \%$ & & & \\
\hline Takahashi K et al. [28] & 1.000 & & & & $31 \%$ \\
\hline Lee KE et al. [37] & 119 & $2.50 \%$ & $94.17 \%$ & $3.33 \%$ & $34.34 \%$ \\
\hline Esen $\mathrm{G}$ et al. [26] & 198 & & & & $20.70 \%$ \\
\hline Kettriz U et al. [15] & 500 & $19 \%$ & $35 \%$ & $100 \%$ & $33 \%$ \\
\hline Kikuchi M et al. [13] & 51 & $23.72 \%$ & & & \\
\hline Bae S et al. [9] & 249 & & & & $23.70 \%$ \\
\hline Travade A et al. [29] & 200 & & & & $25 \%$ \\
\hline Michel SC et al. [30] & 135 & $8 \%$ & $25 \%$ & $100 \%$ & $22 \%$ \\
\hline Atasoy MM et al. [24] & 66 & & $22.73 \%$ & & \\
\hline Kaltenbach B et al. [25] & 849 & & $32.66 \%$ & $90 \%$ & $32 \%$ \\
\hline Grimm LJ et al. [31] & 215 & & & & $34 \%$ \\
\hline Obenauer S et al. [14] & 86 & $4 \%$ & & & \\
\hline Suzuki K et al. [32] & 39 & & & & $28 \%$ \\
\hline Safioleas PM et al. [33] & 853 & & & & $19.20 \%$ \\
\hline Lopez-Ruiz JA et al. & 1.106 & $14.84 \%$ & $35.80 \%$ & $93.21 \%$ & $38.34 \%$ \\
\hline
\end{tabular}

PPV: Positive Predictive Value, n: cases, BI-RADS: Breast Imaging Reporting and Data System 
samples, we believe that they depend on the size of the lesion, as well as the course/performance of the procedure. The "complete" removal of the radiological calcifications does not seem to be the key to avoid underestimation or false negative cases [26,34-36], although some authors [35] reach better results with this action.

The influence of the calibre of the needle used in the SVAB results has been debated in several studies [5,6,37-40], with variable conclusions. Like other authors [41], we found no significant difference in diagnostic value between the two types of needles used, with $11 \mathrm{G}$ (mammotome ${ }^{\circ}$ ) and $10 \mathrm{G}$ (vacora).

It has also been written $[42,43]$ about the possible advantages of segregating samples containing calcifications from those that do not contain them, without agreement in this respect. We not do it, and the results obtained can be considered satisfactory, in relation to other published series.

Our rate of false negatives (10 cases) has been $1.47 \%$, lower than in other series $[9,44]$ (Table 3 ). In this sense, it should be taken into account that, in 8 cases (out of a total of 10), there was a non-infiltrating malignant lesion in surgery, and that in 3 cases, the diagnosis obtained with SVAB was "high-risk" lesions (2 cases of atypical epithelial hyperplasia and 1 case of papillomatosis). According to the opinion of some authors [44], the percentage of false negatives observed in the SVAB of the calcifications is similar to the other types of lesions (mass, architectural distortion, etc).

Infiltrating status has been underestimated in $4.76 \%$ of the cases, which can be considered a good result, when compared with the results published to date $[9,26,28,45]$ (Table 3 ), although the underestimation criteria are not totally coincident in all the series consulted.

The general diagnostic value of our Unit has not been operatordependent, a very positive and desirable circumstance, and it is probably linked to the small number of radiologists (two) which carry out the SVAB procedure.

With the exception of Safioleas PM, et al. [33], it has not been possible to compare our diagnostic parameters with those of other published series, since they do not specify all parameters related specifically to calcifications. In general terms, our results are similar

Table 3. False negatives and underestimation: comparison with other series

\begin{tabular}{|c|c|}
\hline False Negatives & RATE \\
\hline SERIES & $1.20 \%$ \\
\hline Jackman RJ et al. [44] & $4.30 \%$ \\
\hline Bae S et al. [9] & $5.40 \%$ \\
\hline Penco S et al. [35] & $2.40 \%$ \\
\hline Safioleas PM et al. [33] & $1.47 \%$ \\
\hline Lopez-Ruiz JA et al. & \\
\hline Underestimation & RATE \\
\hline SERIES & $6.10 \%$ \\
\hline Esen G et al. [26] & $8.60 \%$ \\
\hline Bae S et al. [9] & $9.90 \%$ \\
\hline Timpe L et al. [45] & $17.00 \%$ \\
\hline Takahashi K et al. [28] & $17.90 \%$ \\
\hline Penco S et al. [35] ${ }^{(1)}$ & $21.40 \%$ \\
\hline Penco S et al. [35] ${ }^{(2)}$ & $10.80 \%$ \\
\hline Zagouri F et al. [43] $^{\text {Zafioleas PM et al. [33] }}$ & $4.60 \%$ \\
\hline Lopez-Ruiz JA et al. & $4.76 \%$ \\
\hline
\end{tabular}

(1) DCIS (Ductal Carcinoma in Situ)

(2) LCIS (Lobular Carcinoma in Situ) to those Safioleas PM et al (sensitivity $98.2 \%$, specificity $100 \%$, positive predictive value $100 \%$ and negative predictive value $97.6 \%$ ) and can be considered satisfactory.

\section{Conclusions}

1) In an Interventional Breast Unit, which has easy access to patients coming from different Centers, there is an important indication of SVAB on Category 3 lesions (BI-RADS), due to great inter-observer variability and, on the other hand, the patient's preferences: they prefer the biopsy, rather than the radiological follow-up.

2) Positive predictive value for malignancy of Category 3 lesions, $14.84 \%$, is markedly higher than that reported classically, which reflects the inter-observer variability.

3) SVAB is an effective and efficient method for the diagnostic management of suspicious calcifications.

\section{Acknowledgment}

We thank Belén Oruetxebarría and Garbiñe Sarriugarte, responsible in Bizkaia and the Basque Country, respectively, of the Breast Cancer Early Detection Program, for their collaboration in the collection of data on surgery and patient follow-up. We also thank Iratxe Lafuente Guerrero, from the Research and Epidemiology Unit of Galdakao Hospital, for his work in the elaboration of the database used.

\section{References}

1. Sickles, EA, D’Orsi CJ, Bassett LW, et al. (2013) ACR BI-RADS® Mammography. In: ACR BI-RADS ${ }^{\circledR}$ Atlas, Breast Imaging Reporting and Data System. Reston, VA, American College of Radiology.

2. Fahrbach K, Sledge I, Cella C, Linz H, Ross SD (2006) A comparison of the accuracy of two minimally invasive breast biopsy methods: a systematic literature review and meta-analysis. Arch Gynecol Obstet 274: 63-73. [Crossref]

3. Houssami N, Ciatto S, Ellis I, Ambrogetti D (2007) Underestimation of malignancy of breast core-needle biopsy: concepts and precise overall and category-specific estimates. Cancer 109: 487-495. [Crossref]

4. Ciatto S, Houssami N, Ambrogetti D, Bianchi S, Bonardi R, et al. (2007) Accuracy and underestimation of malignancy of breast core needle biopsy: the Florence experience of over 4000 consecutive biopsies. Breast Cancer Res Treat 101: 291-297. [Crossref]

5. Liberman L, Gougoutas CA, Zakowski MF, La Trenta LR, Abramson AF, et al. (2001) Calcifications highly suggestive of malignancy: comparison of breast biopsy methods. AJR Am J Roentgenol 177: 165-172. [Crossref]

6. Ames V, Britton PD (2011) Stereotactically guided breast biopsy: a review. Insights Imaging 2: 171-176. [Crossref]

7. Fernández-García P, Marco-Doménech SF, Lizán-Tudela L, Ibáñez-Gual MV Navarro-Ballester A, et al. (2017) The cost effectiveness of vacuum-assisted versus core-needle versus surgical biopsy of breast lesions. Radiología 59: 40-46. [Crossref]

8. Keränen AK, Haapea M, Rissanen T (2015) Ultrasonography as a guiding method in breast micro-calcification vacuum-assisted biopsies. Ultraschall Med. [Crossref]

9. Bae S, Yoon JH, Moon HJ, Kim MJ, Kim EK (2015) Breast microcalcifications diagnostic outcomes according to image-guided biopsy method. Korean J Radiol 16: 996-1005. [Crossref]

10. Schrading S, Distelmaier M, Dirrichs T, Detering S, Brolund L, et al. (2015) Digital breast tomosynthesis-guided vacuum-assisted breast biopsy: initial experiences and comparison with prone stereotactic vacuum-assisted biopsy. Radiology 274: 654-662. [Crossref]

11. Lee AY, Wisner DJ, Aminololama-Shakeri S, Arasu VA, Feig SA, et al. (2017) Inter-reader variability in the use of BI-RADS descriptors for suspicious findings on diagnostic mammography: a multi-institution study of 10 academic radiologists. Acad Radiol 24: 60-66. [Crossref]

12. Mendez A, Cabanillas F, Echenique M, Malekshamran K, Perez I, et al. (2004) Evaluation of Breast Imaging Reporting and Data System Category 3 mammograms and the use of stereotactic vacuum-assisted breast biopsy in a nonacademic community practice. Cancer 100: 710-714. [Crossref] 
13. Kikuchi M, Tsunoda-Shimizu H, Kawasaki T, Suzuki K, Nakamura S, et al. (2007) Indications for stereotactically-guided vacuum-assisted breast biopsy for patients with category 3 microcalcifications. Breast Cancer 14: 285-291. [Crossref]

14. Obenauer S, Fischer U, Baum F, Dammert S, Füzesi L, et al. (2001) [Stereotactic vacuum core biopsy of clustered microcalcifications classified as B1-RADS 3]. Rofo 173: 696-701. [Crossref]

15. Kettriz U, Morack G, Decker T (2005) Stereotactic vacuum - assisted in 500 women with microcalcifications : radiological and pathological correlations. Eur J Radiol 55: 270-276. [Crossref]

16. Varas X, Leborgne JH, Leborgne F, Mezzera J, Jaumandreu S, et al. (2002) Revisiting the mammographic follow-up of BI-RADS category 3 lesions. AJR Am J Roentgenol 179: 691-695. [Crossref]

17. Henrot P, Leroux A, Barlier C, Génin P (2014) Breast microcalcifications: the lesions in anatomical pathology. Diagn Interv Imaging 95: 141-152. [Crossref]

18. Cox RF, Hernandez-Santana A, Ramdass S, McMahon G, Harmey JH, et al. (2012) Microcacifications in breast cancer: novel insights into the molecular mechanism and functional consequence of mammary mineralization. Br J Cancer 106: 525-537. [Crossref]

19. Scimeca M, Giannini E, Antonacci C, Pistolese CA, Spagnoli LG, et al. (2014) Microcalcifications in breast cancer: an active phenomenon mediated by epithelial cells with mesenchymal characteristics. BMC Cancer 14: 286. [Crossref]

20. Selim A, Tahan SR (1998) Microscopic localization of calcifications in and around breast carcinoma: a cautionary note for needle core biopsies. Ann Surg 228: 95-98. [Crossref]

21. Castellaro AM, Tonda A, Cejas HH, Ferreyra H, Caputto BL, et al. (2015) Oxalate induces breast cancer. BMC Cancer 15: 761. [Crossref]

22. Sathyavathi R, Saha A, Soares JS, Spegazzini N, McGee S, et al. (2015) Raman spectroscopic sensing of carbonate intercalation in breast microcalcifications at stereotactic biopsy. Sci Rep 5: 9907. [Crossref]

23. Kayhan A, Aribal E, Sahin C, Tasci ÖC, Özkan Gürdal S, et al. (2016) Radiological findings of screen-detected cancers in an organized population-based screening mammography program in Turkey. Diagn Interv radiol 22: 508-513. [Crossref]

24. Atasoy MM, Tasali N, Cubuk R, Narin B, Deveci U,et al. (2015) Vacuum-assisted stereotactic biopsy for isolated BI-RADS 4 microcalcifications: evaluation with histopathology and midterm follow-up results. Diagn Interv Radiol 21: 22-27. [Crossref]

25. Kaltenbach B, Brandenbusch V, Möbus V, Mall G, Falk S, et al. (2017) A matrix of morphology and distribution of calcifications in the breast: Analysis of 849 vacuumassisted biopsies. Eur J Radiol 86: 221-226. [Crossref]

26. Esen G, Tutar B, Uras C, Calay Z, İnce Ü, et al. (2016) Vacuum-assisted stereotactic breast biopsy in the diagnosis and management of suspicious microcalcifications. Diagn Interv Radiol 22: 326-333. [Crossref]

27. Buchbinder SS, Leichter IS, Lederman RB, Novak B, Bamberger PN, et al. (2004) Computer-aided classification of BI-RADS category 3 breast lesions. Radiology 230 : 820-823. [Crossref]

28. Takahashi K, Gomi N, Iwase T, Sakamoto G (2006) The role and efficacy of Mammotome biopsy (vacuum-assisted breast biopsy. Nippon Rinsho 64: 469-474. [Crossref]

29. Travade A, Isnard A, Bagard C, Bouchet F, Chouzet S, et al. (2002) [Stereotactic 11 -gauge directional vacuum-assisted breast biopsy: experience with 249 patients]. $J$ Radiol 83: 1063-1071. [Crossref]
30. Michel SC, Löw R, Singer G, Otto R, Hohl M, et al. (2007) [Stereotactic Mammotome breast biopsy: routine clinical experience and correlation with BI-RADS--classification and histopathology]. Praxis (Bern 1994) 96: 1459-1474. [Crossref]

31. Grimm LJ, Johnson DY, Johnson KS, Baker JA, Soo MS, et al. (2016) Suspicious breast calcifications undergoing stereotactic biopsy in women ages 70 and over: Breast cancer incidence by BI-RADS descriptors. Eur Radiol 27: 2275-2281. [Crossref]

32. Suzuki K, Shiraishi A, Arakawa A (2009) Analysis of stereotactic vacuum-assisted breast biopsy for patients with segmental calcifications. Jpn J Radiol 27: 450-454. [Crossref]

33. Safioleas PM, Koulocheri D, Michalopoulos N, Liacou P, Flessas I, et al. (2017) The value of stereotactic vacuum assisted breast biopsy in the investigation of microcalcifications. A six-year experience with 853 patients. J BUON 22: 340-346. [Crossref]

34. Lomoschitz F M, Helbich T H, Rudas M, Pfarl G, Linnau K F, et al. (2004) Stereotactic 11- gauge Vacuum-assisted Breast Biopsy: Influence of Number of Number of Specimens on Diagnostic Accuracy. Radiology. 232: 897-903. [Crossref]

35. Penco S, Rizzo S, Bozzini AC, Latronico A, Menna S, et al. (2010) Stereotactic vacuumassisted breast biopsy is not a therapeutic procedure even when all mammographically found calcifications are removed: analysis of 4,086 procedures. AJR Am J Roentgenol 195: 1255-1260. [Crossref]

36. Youn I, Kim MJ, Moon HJ, Kim EK (2014) Absence of residual microcalcifications in atypical ductal hyperplasia diagnosed via stereotactic vacuum-assisted breast biopsy: is surgical excision obviated? J Breast Cancer 17: 265-269. [Crossref]

37. Lee KE, Kim HH, Shin HJ, Cha JH (2013) Stereotactic biopsy of the breast using a decubitus table: comparison of histologic underestimation rates between 11- and 8-gauge vacuum-assisted breast biopsy. Springerplus 2: 551. [Crossref]

38. Preibsch H, Baur A, Wietek BM, Krämer B, Staebler A, et al. (2015) Vacuum-assisted breast biopsy with 7-gauge, 8 -gauge, 9-gauge, 10-gauge, and 11-gauge needles: how many specimens are necessary? Acta Radiol 56: 1078-1084. [Crossref]

39. Venkataraman S, Dialani V, Gilmore HL, Mehta TS (2012) Stereotactic core biopsy: Comparison of 11 gauge with 8 gauge vacuum assisted breast biopsy. Eur J Radiol 81: 2613-2619. [Crossref]

40. Heller SL, Jaglan S, Babb JS, Melsaether A, Toth HB, et al. (2016) Frequency of discordant lesions and false-negative cancers at stereotactic vacuum-assisted biopsy. Acad Radiol 23: 994-9. [Crossref]

41. Pistolese CA1, Ciarrapico AM, Della Gatta F, Perretta T, Cossu E, et al. (2009) Costeffectiveness analysis of two vacuum-assisted breast biopsy systems: Mammotome and Vacora. Radiol Med 114: 743-756. [Crossref]

42. Easley S, Abdul-Karim FW, Klein N, Wang N (2007) Segregation of radiographic calcifications in stereotactic core biopsies of breast: is it necessary? Breast J. 13: 486-9. [Crossref]

43. Zagouri F, Sergentanis TN, Nonni A, Koulocheri D, Fotou M, et al. (2007) Vacuumassisted breast biopsy: The value and limitations of cores with microcalcifications. Pathol Res Pract 203: 563-566. [Crossref]

44. Jackman RJ, Marzoni FA Jr, Rosenberg J (2009) False-negative diagnoses at stereotactic vacuum-assisted needle breast biopsy: long-term follow-up of 1,280 lesions and review of the literature. AJR Am J Roentgenol 192: 341-351. [Crossref]

45. Timpe L, Berkemeyer S, Puesken M, Tio J, Heindel W, et al. (2015) Rates of presurgical underestimation of breast cancer after standardized assessment of breast calcifications. Rofo 187: 445-449. [Crossref]

Copyright: (C2018 López-Ruiz JA. This is an open-access article distributed under the terms of the Creative Commons Attribution License, which permits unrestricted use, distribution, and reproduction in any medium, provided the original author and source are credited. 